Virginia Commonwealth University VCU Scholars Compass

2011

\title{
Photoelectron spectroscopic study of iron-pyrene cluster anions
}

\author{
Xiang Li \\ Johns Hopkins University \\ Kit H. Bowen Jr. \\ Johns Hopkins University, kbowen@jhu.edu \\ Puru Jena \\ Virginia Commonwealth University, pjena@vcu.edu \\ Anil K. Kandalam \\ McNeese State University
}

Follow this and additional works at: http://scholarscompass.vcu.edu/phys_pubs

Part of the Physics Commons

Li, X., Bowen Jr, K. H., \& Jena, P., et al. Photoelectron spectroscopic study of iron-pyrene cluster anions. The Journal of Chemical Physics, 135, 204301 (2011). Copyright (C) 2011 American Institute of Physics.

\section{Downloaded from}

http://scholarscompass.vcu.edu/phys_pubs/161

This Article is brought to you for free and open access by the Dept. of Physics at VCU Scholars Compass. It has been accepted for inclusion in Physics Publications by an authorized administrator of VCU Scholars Compass. For more information, please contact libcompass@vcu.edu. 


\title{
Photoelectron spectroscopic study of iron-pyrene cluster anions
}

\author{
Xiang Li, ${ }^{1}$ Kit H. Bowen, Jr., ${ }^{1, a)}$ Puru Jena, ${ }^{2}$ and Anil K. Kandalam ${ }^{3, a)}$ \\ ${ }^{1}$ Departments of Chemistry and Material Sciences, Johns Hopkins University, Baltimore, \\ Maryland 21218, USA \\ ${ }^{2}$ Department of Physics, Virginia Commonwealth University, Richmond, Virginia 23284, USA \\ ${ }^{3}$ Department of Physics, McNeese State University, Lake Charles, Louisiana 70609, USA
}

(Received 20 July 2011; accepted 27 October 2011; published online 22 November 2011)

\begin{abstract}
Iron-pyrene cluster anions, $\left.\left[\mathrm{Fe}_{\mathrm{m}} \text { (pyrene }\right)_{\mathrm{n}}\right]^{-}(\mathrm{m}=1-2, \mathrm{n}=1-2)$ were studied in the gas phase by photoelectron spectroscopy, resulting in the determination of their electron affinity and vertical detachment energy values. Density functional theory calculations were also conducted, providing the structures and spin multiplicities of the neutral clusters and their anions as well as their respective electron affinity and vertical detachment energy values. The calculated magnetic moments of neutral $\mathrm{Fe}_{1}$ (pyrene) $)_{1}$ and $\mathrm{Fe}_{2}$ (pyrene) $)_{1}$ clusters suggest that a single pyrene molecule could be a suitable template on which to deposit small iron clusters, and that these in turn might form the basis of an iron cluster-based magnetic material. A comparison of the structures and corresponding photoelectron spectra for the iron-benzene, iron-pyrene, and iron-coronene cluster systems revealed that pyrene behaves more similarly to coronene than to benzene. (C) 2011 American Institute of Physics. [doi:10.1063/1.3661984]
\end{abstract}

\section{INTRODUCTION}

Transition metal-organic molecular complexes play an important role in the field of organometallic chemistry because of their unique structural, electronic and magnetic properties. Many experimental and theoretical studies have provided information regarding the interactions between various transition metals and organic ligands, such as benzene, ${ }^{1-21}$ pyridine, ${ }^{22}$ fullerene $\left(\mathrm{C}_{60}\right),{ }^{6,15,23-31}$ coronene, ${ }^{15,32-42}$ cyclooctatetrene (COT), ${ }^{6,43,44}$ and pyrene. ${ }^{37,45,46,49}$ Most of these studies have focused on characterizing the bonding between the d-electrons in the subject transition metals and the $\pi$ electrons of the organic ligands. Since the per atom magnetic moments of transition metal clusters are often larger than those exhibited by the same metal in its condensed state, ${ }^{47}$ organic ligands may be able to help some metal clusters retain their high per atom magnetic moments, and this could lead to the synthesis of novel magnetic materials.

As the simplest of the transition metal-organic complexes, gas phase transition metal-benzene complexes have been extensively studied. ${ }^{1-16}$ Kaya, Nakajima, and coworkers ${ }^{5,6}$ suggested that these complexes could form either sandwich or "rice-ball" (metal cluster core covered by benzene molecules) structures depending on the number of $\mathrm{d}$ electrons of the transition metal. Duncan and co-workers have conducted photodissociation studies of positively-charged transition metal-benzene complexes, ${ }^{13-16}$ and our own group has carried out photoelectron spectroscopic studies on negatively-charged transition metalbenzene complexes. ${ }^{9-12}$ On the theoretical side, Jena and co-workers ${ }^{17-21}$ have performed theoretical calculations to the $\mathrm{V}-, \mathrm{Fe}-$, Ni-benzene systems in order to elucidate their structural and magnetic properties.

\footnotetext{
a) Authors to whom correspondence should be addressed. Electronic addresses: kbowen@jhu.edu and akandalam@mcneese.edu.
}

Studies of metal-polycyclic aromatic hydrocarbons (PAHs) have also attracted broad attention. PAHs are molecules that consist of fused aromatic rings; these can be viewed as extended benzene systems or as finite size sub-sections of graphite or nanotubes. These compounds are among the most widespread organic pollutants, these being formed by incomplete combustion of carbon-containing fuels such as wood, coal, and tobacco. PAHs are also found in the interstellar medium, in comets, and in meteorites, and they may have been important in primordial biochemistry. Metal-PAH complexes are thought to be able to exhibit multiple sandwich structures. In addition, the formation of metal-PAH complexes may be responsible for the depletion of metals in interstellar gas clouds. ${ }^{48}$ Dunbar and coworkers ${ }^{32}$ generated the complexes of $\mathrm{Sc}^{+}, \mathrm{Mn}^{+}$, and several other metals with one or more coronene molecules. Duncan and co-workers, ${ }^{15,33-39}$ reported photodissociation studies of $\mathrm{Sc}$ (coronene $)_{1,2}{ }^{+}, \mathrm{Mn}$ (coronene $)_{1,2}{ }^{+}, \mathrm{Cr}_{\mathrm{m}}$ (coronene $)_{\mathrm{n}}{ }^{+}$ $(\mathrm{m}=1-5, \mathrm{n}=1-3), \mathrm{Ag}_{\mathrm{m}}(\text { coronene })_{\mathrm{n}}{ }^{+}(\mathrm{m}=1-3, \mathrm{n}=1-4)$, $\mathrm{Fe}_{\mathrm{m}}$ (coronene $)_{\mathrm{n}}{ }^{+}(\mathrm{m}=1-3, \mathrm{n}=1-5), \mathrm{Ca}_{\mathrm{m}}(\text { coronene })_{\mathrm{n}}{ }^{+}$, and $\mathrm{Nb}$-(coronene) ${ }^{+}$systems. Photoelectron spectroscopic studies on negatively charged transition metal-coronene complexes have been conducted by Kaya, Nakajima, and coworkers. ${ }^{35}$ The current authors have carried out joint experimental and theoretical studies on the $\mathrm{Co}_{\mathrm{m}}$ (coronene $)_{\mathrm{n}}{ }^{41}$ and $\mathrm{Fe}_{\mathrm{m}}$ (coronene $)_{\mathrm{n}}{ }^{42}$ cluster anions. Based on our results, a common structural feature emerged, namely, the metal atoms dimerize while interacting with the coronene molecule. More importantly, the $\mathrm{Fe}_{2}$ and $\mathrm{Co}_{2}$ dimers retain their magnetic moments when supported on a coronene molecule. In addition, our results showed that $\left.\left[\mathrm{Fe}_{1} \text { (coronene }\right)_{2}\right]^{-}$, $\left.\left[\mathrm{Fe}_{2} \text { (coronene }\right)_{2}\right]^{-}$, and their corresponding neutrals clusters prefer sandwich structures.

Pyrene is a polyaromatic hydrocarbon which is larger than benzene but smaller than coronene. Previously, 
Duncan and co-workers $37,39,46$ reported photodissociation studies on positively charged $\mathrm{Nb}$-pyrene, Fe-pyrene, and $\mathrm{Ca}-$ pyrene complexes. Recently, a joint experimental and theoretical study was reported by the current authors focusing on the geometrical and electronic structures as well as the magnetic properties of $\mathrm{Co}_{\mathrm{m}}(\text { Pyrene })_{\mathrm{n}}$ clusters. ${ }^{49}$ In the present paper, we report the photoelectron spectroscopic study of the negatively charged $\left[\mathrm{Fe}_{\mathrm{m}}(\text { pyrene })_{\mathrm{n}}\right]^{-}(\mathrm{m}=1-2 ; \mathrm{n}=1-2)$ complexes. A comparison between the results of this work and our previous studies of iron-benzene and iron-coronene complexes assists in building a fuller picture of the interaction between the iron atoms/clusters and aromatic hydrocarbon networks.

\section{METHODOLOGIES}

\section{Experimental}

A laser vaporization source was utilized to produce $\left[\mathrm{Fe}_{\mathrm{m}}(\text { pyrene })_{\mathrm{n}}\right]^{-}(\mathrm{m}=1-2, \mathrm{n}=1-2)$ cluster anions. The same source was used to generate Fe-coronene cluster anions. ${ }^{42}$ In this source, an Nd:YAG laser operating at $532 \mathrm{~nm}$ was used to ablate a rotating, translating, pyrene-coated iron rod. Helium gas at $\sim 4$ atm from a pulsed valve cooled and also transported the resultant cluster anions. These were then extracted into a linear time-of-flight mass spectrometer (mass resolution of $\sim 600$ ), mass-selected, and photodetached with the third harmonic frequency $(355 \mathrm{~nm}, 3.49 \mathrm{eV})$ of another Nd:YAG laser. The resulting photodetached electrons were then energy-analyzed with a magnetic bottle, electron energy analyzer having a resolution of $\sim 35 \mathrm{meV}$ at EKE $=1 \mathrm{eV}$. The photodetachment process is governed by the energy-conserving relationship, $h v=\mathrm{EBE}+\mathrm{EKE}$, where $h v$ is the photon energy, EBE is the electron binding energy, and EKE is the electron kinetic energy. Our apparatus has been described in detail in Ref. 9.

\section{Computational}

In order to identify the ground state geometries and the preferred spin states of these metal-organic complexes, we have carried out density functional theory based electronic structure calculations on neutral and anionic iron-pyrene complexes using the GAUSSIAN 03 program. ${ }^{50}$ The hybrid density functional, B3LYP ${ }^{51,52}$ along with the frozen-core Lanl2dz basis set (for iron atom) and an all electron 6-311G** basis (for carbon and hydrogen atoms) were employed for all the calculations. The equilibrium geometries of iron-pyrene complexes were obtained by carrying out geometry optimization, without any symmetry constraint, on various structural isomers and for different spin multiplicities $(2 S+1)$. The convergence for total energy and gradient were set to $10^{-9}$ Hartree and $10^{-4}$ Hartree/ $\AA$, respectively. The accuracy and reliability of our basis set has been established in our previous studies $^{41,42,49}$ on various metal-organic complexes. The stabilities of the lowest energy isomers found in this work have been verified by carrying out vibrational frequency calculations. The vertical detachment energies (VDE) and the electron affinities (EA) of these metal-organic complexes were calculated and compared with the measured values. When the energy difference between two isomers is less than the uncertainty in the computational method $(\Delta \mathrm{E}=0.20 \mathrm{eV})$, the electron detachment energies were calculated for both the isomers.

\section{RESULTS AND DISCUSSION}

The electron affinity and the vertical detachment energy are two important parameters that can often be determined through anion photoelectron spectroscopic experiments. The EA is defined as the energy difference between the ground state geometries of neutral and anionic clusters. The VDE is the energy difference between the anion and the neutral, both at the geometry of the ground state anion. When there are minimal vibrational hot bands and significant Franck-Condon overlap, the EBE value at which there is an onset of photoelectron signal provides the EA value. The EBE of the intensity maximum in the lowest EBE band provides the VDE value. The photoelectron spectra of $\left[\mathrm{Fe}_{\mathrm{m}}(\text { pyrene })_{\mathrm{n}}\right]^{-}(\mathrm{m}=1-$ $2 ; \mathrm{n}=1-2$ ) complexes are shown in Figure 1. Table I shows the experimental and the corresponding calculated EA values of neutral $\mathrm{Fe}_{\mathrm{m}}$ (pyrene) $)_{\mathrm{n}}$, and the VDE values of anionic $\left[\mathrm{Fe}_{\mathrm{m}}(\text { pyrene })_{\mathrm{n}}\right]^{-}$. Since pyrene is an extended carbon network with characteristics that lie between benzene and coronene, we also included the photoelectron spectra of the corresponding $\left[\mathrm{Fe}_{\mathrm{m}}(\text { benzene })_{\mathrm{n}}\right]^{-}$and $\left[\mathrm{Fe}_{\mathrm{m}}(\text { coronene })_{\mathrm{n}}\right]^{-}$cluster anions in Figure 1 for comparison. ${ }^{12,42}$ Table II presents a comparison of the experimentally-determined EA and VDE values for all twelve complexes. The calculated neutral and anionic geometric structures of $\mathrm{Fe}_{1}$ (pyrene) $)_{1}, \mathrm{Fe}_{2}$ (pyrene) $)_{1}$, $\mathrm{Fe}_{1}$ (pyrene) $)_{2}$, and $\mathrm{Fe}_{2}$ (pyrene) $)_{2}$ clusters, along with their calculated spin multiplicities are presented in Figures 2-5 respectively. The spin magnetic moment of each system, in units of Bohr magnetons, $\mu_{\mathrm{B}}$, is equal to the spin multiplicity minus one, i.e., $(2 \mathrm{~S}+1)-1=2 \mathrm{~S}$. The neutral and anionic ironpyrene clusters that we studied in this work are discussed below.

\section{$\mathrm{Fe}_{1}(\text { pyrene })_{1}$ and $\left[\mathrm{Fe}_{1}(\text { pyrene })_{1}\right]^{-}$}

The photoelectron spectrum of $\left.\left[\mathrm{Fe}_{1} \text { (pyrene) }\right]_{1}\right]^{-}$shows at least two distinct spectral features (Figure 1). The first peak is located at $\mathrm{EBE}=1.09 \mathrm{eV}$, and this corresponds to the VDE value for $\left.\left[\mathrm{Fe}_{1} \text { (pyrene }\right)_{1}\right]^{-}$. The second feature is a combination of at least two peaks, located at $\mathrm{EBE}=1.46 \mathrm{eV}$ and $1.60 \mathrm{eV}$. The EA of the $\mathrm{Fe}_{1}$ (pyrene) ${ }_{1}$ neutral is estimated based on the EBE onset of the first peak, which is $0.91 \mathrm{eV}$.

Our calculations show two energetically degenerate isomers for anions; while there are three isoenergetic isomers in the neutral cluster (see Figure 2). In all of these structures, irrespective of charge, the iron atom binds with either $\eta^{2}$ - or $\eta^{3}$-coordination to a ring of the pyrene molecule. Both the isomers of $\left.\left[\mathrm{Fe}_{1} \text { (pyrene }\right)_{1}\right]^{-}$cluster prefers a quartet spin state $(2 S+1=4)$. In the case of Isomer-1, the doublet spin state $(2 \mathrm{~S}+1=2)$ is $0.30 \mathrm{eV}$ higher in energy, while in Isomer-2, the doublet is $0.56 \mathrm{eV}$ higher in energy than their corresponding quartet spin states. The lowest 

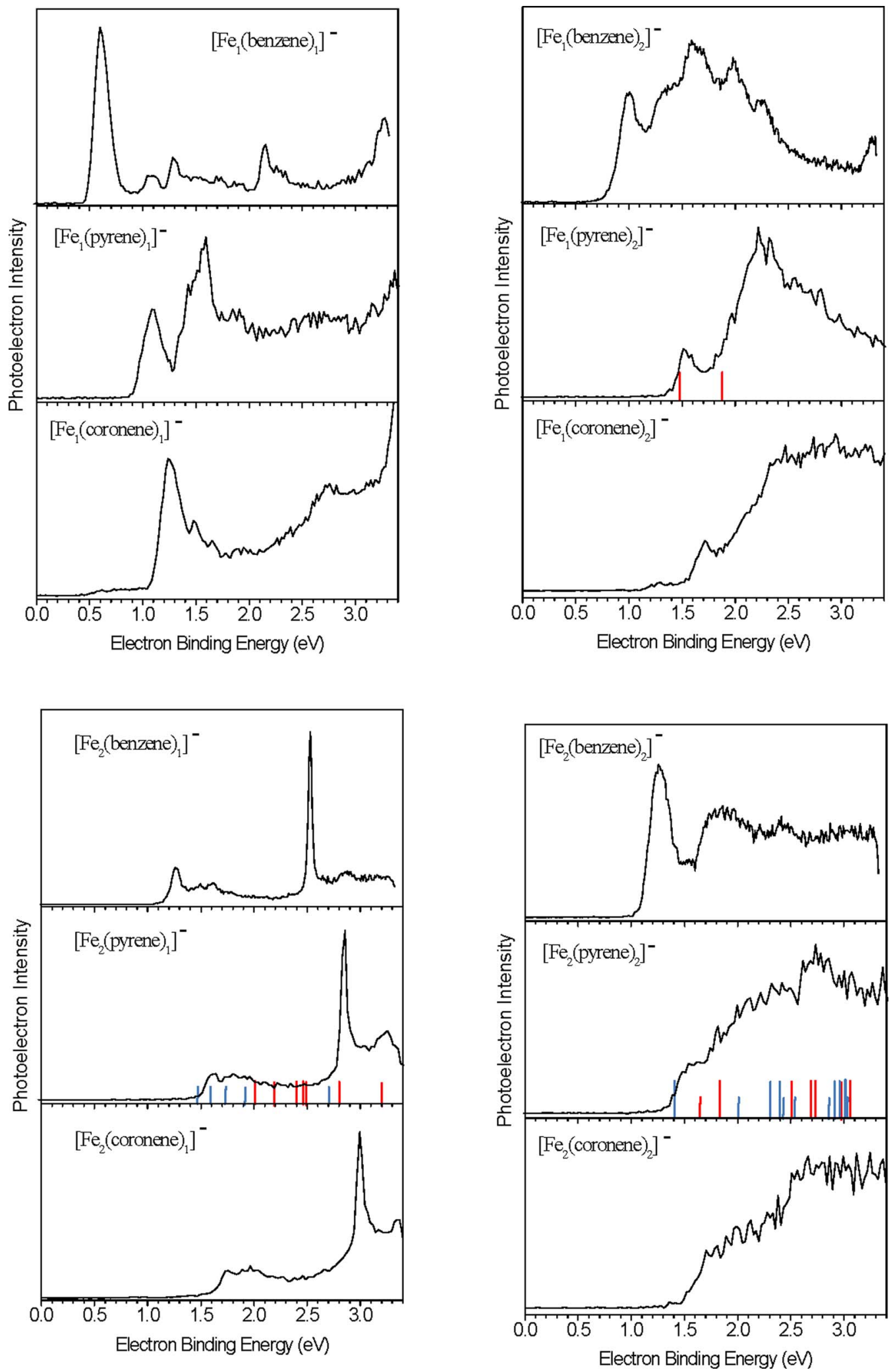

FIG. 1. The photoelectron spectra of $\left[\mathrm{Fe}_{\mathrm{m}}(\text { Organic })_{\mathrm{n}}\right]^{-}($Organic $=$benzene, pyrene, and coronene, $\mathrm{m}=1-2 ; \mathrm{n}=1-2)$ anionic complexes. The calculated electron detachment energies for $\left[\mathrm{Fe}_{\mathrm{m}}(\text { pyrene })_{\mathrm{n}}\right]^{-}$systems are also marked in the spectra.

energy isomer of $\left.\left[\mathrm{Fe}_{1} \text { (pyrene }\right)_{1}\right]^{-}$cluster is similar to that of the previously reported ${ }^{49} \mathrm{Co}(\text { pyrene })^{-}$cluster. Since, the energy difference between the two isomers of the anion is within the computational uncertainty $(\sim 0.20 \mathrm{eV})$; the electron verti- cal detachment energies were calculated for both the isomers. For Isomer-1, in which the $\mathrm{Fe}$ atom has $\eta^{3}$-coordination, the electron detachment energies are calculated to be $1.18 \mathrm{eV}$ and $1.43 \mathrm{eV}$, corresponding to the transition from anionic quar- 
TABLE I. The experimentally determined and theoretically predicted EA and VDE values for $\mathrm{Fe}_{\mathrm{m}}$ (pyrene) $)_{\mathrm{n}}(\mathrm{m}=1-2 ; \mathrm{n}=1-2)$ systems (uncertainty of $\pm 0.10 \mathrm{eV})$.

\begin{tabular}{|c|c|c|c|c|}
\hline & \multicolumn{2}{|c|}{$\begin{array}{l}\text { EA } \\
(\mathrm{eV})\end{array}$} & \multicolumn{2}{|c|}{$\begin{array}{l}\text { VDE } \\
(\mathrm{eV})\end{array}$} \\
\hline & Expt. & Theo. & Expt. & Theo. \\
\hline $\mathrm{Fe}_{1}$ (pyrene) $)_{1}$ & 0.91 & 0.97 & 1.09 & $\begin{array}{l}\text { Isomer-1: } 1.18 \\
\text { Isomer-2: } 1.24\end{array}$ \\
\hline $\mathrm{Fe}_{2}$ (pyrene) $)_{1}$ & 1.50 & 1.31 & 1.62 & $\begin{array}{l}\text { Isomer-1: } 1.42 \\
\text { Isomer-2: } 1.30\end{array}$ \\
\hline $\mathrm{Fe}_{1}$ (pyrene) $)_{2}$ & 1.40 & 1.24 & 1.51 & $\begin{array}{l}\text { Isomer-1: } 1.40 \\
\text { Isomer-2: } 1.84\end{array}$ \\
\hline $\mathrm{Fe}_{2}$ (pyrene) $)_{2}$ & 1.33 & 1.10 & $\sim 1.6$ & $\begin{array}{l}\text { Isomer-1: } 1.62 \\
\text { Isomer-2: } 1.40\end{array}$ \\
\hline
\end{tabular}

tet to the neutral quintet and from anionic quartet to the neutral triplet, respectively. While, for Isomer-2, the corresponding detachment energies are $1.24 \mathrm{eV}$ (quartet to quintet) and $1.60 \mathrm{eV}$ (quartet to triplet). It is to be noted here that the first peak on the photoelectron spectrum of $\left.\left[\mathrm{Fe}_{1} \text { (pyrene }\right)_{1}\right]^{-}$cluster is broad with energy ranging from $1.1 \mathrm{eV}$ to $1.4 \mathrm{eV}$. The broadening of the first peak can be due to the overlap of the transitions from both the isomers, with the calculated transition energies of $1.18 \mathrm{eV}$ from Isomer- 1 and $1.24 \mathrm{eV}$ from Isomer-2. Thus, the first peak of the photoelectron spectrum is due to the electron detachment from the $\beta$-MO of both the Isomer-1 and Isomer-2. Furthermore, the higher energy peak $(\mathrm{EBE}=1.46 \mathrm{eV})$ corresponds to the electron detachment from the $\alpha-\mathrm{MO}$ of Isomer-1 (calculated: $1.40 \mathrm{eV}$ ), while the peak with $\mathrm{EBE}=1.60 \mathrm{eV}$ is due to the electron detachment from the $\alpha$-MO of Isomer- 2 (calculated: $1.60 \mathrm{eV}$ ). Thus, both Isomer- 1 and Isomer- 2 are contributing towards the photoelectron spectrum of $\left.\left[\mathrm{Fe}_{1} \text { (pyrene }\right)_{1}\right]^{-}$cluster indicating that both these isomers are present in the anion cluster beam. It is to be noted here that presence of multiple isomers has been reported in our earlier studies ${ }^{42,49}$ of $\mathrm{Fe}$ (coronene) and Co(pyrene) clusters.

The lowest energy isomer of neutral $\mathrm{Fe}_{1}$ (pyrene) cluster is similar to that of its anionic counterpart, albeit with a weaker Fe-pyrene interaction. The three lowest energy isomers of $\mathrm{Fe}_{1}$ (pyrene) $)_{1}$ cluster are similar to that of the previously reported $^{49}$ lowest energy isomers of neutral $\mathrm{Co}_{1}$ (pyrene) $)_{1}$ cluster. Interestingly, the Isomer-3

TABLE II. The experimental EA and the VDE values for $\mathrm{Fe}_{\mathrm{m}}$ (organic $)_{\mathrm{n}}$ $(\mathrm{m}=1-2 ; \mathrm{n}=1-2)$ systems (organic $=$ benzene (Ref. 12), pyrene, and coronene (Ref. 42)).

\begin{tabular}{|c|c|c|c|c|c|}
\hline & $\begin{array}{c}\text { EA } \\
(\mathrm{eV})\end{array}$ & $\begin{array}{l}\text { VDE } \\
(\mathrm{eV})\end{array}$ & & $\begin{array}{c}\text { EA } \\
(\mathrm{eV})\end{array}$ & $\begin{array}{l}\text { VDE } \\
(\mathrm{eV})\end{array}$ \\
\hline $\mathrm{Fe}_{1}$ (benzene) $)_{1}$ & 0.46 & 0.60 & $\mathrm{Fe}_{1}$ (benzene $)_{2}$ & 0.78 & 0.98 \\
\hline $\mathrm{Fe}_{1}(\text { pyrene })_{1}$ & 0.91 & 1.09 & $\mathrm{Fe}_{1}(\text { pyrene })_{2}$ & 1.40 & 1.51 \\
\hline $\mathrm{Fe}_{1}(\text { coronene })_{1}$ & 1.06 & 1.22 & $\mathrm{Fe}_{1}(\text { coronene })_{2}$ & 1.50 & 1.71 \\
\hline $\mathrm{Fe}_{2}$ (benzene $)_{1}$ & 1.15 & 1.26 & $\mathrm{Fe}_{2}$ (benzene $)_{2}$ & 1.08 & 1.25 \\
\hline $\mathrm{Fe}_{2}$ (pyrene) $)_{1}$ & 1.50 & 1.62 & $\mathrm{Fe}_{2}$ (pyrene $)_{2}$ & 1.33 & $\sim 1.6$ \\
\hline $\mathrm{Fe}_{2}(\text { coronene })_{1}$ & 1.59 & 1.73 & $\mathrm{Fe}_{2}(\text { coronene })_{2}$ & 1.48 & $\sim 1.8$ \\
\hline
\end{tabular}

$(\Delta \mathrm{E}=0.16 \mathrm{eV})$ was reported to be the ground state geometry of neutral $\mathrm{Fe}_{1}$ (pyrene) $)_{1}$ cluster in an earlier theoretical study. ${ }^{53}$ Overall, in both neutral and anionic species, the iron atom prefers either $\eta^{3}$ - or $\eta^{2}$-coordination, while binding with pyrene molecule. Our calculated EA value of $0.97 \mathrm{eV}$ is in good agreement with the measured value of $0.91 \mathrm{eV}$. Our calculations show that the neutral $\mathrm{Fe}_{1}$ (pyrene) $)_{1}$ cluster prefers a quintet spin state $(2 S+1=5)$, thus resulting in a spin magnetic moment of $(2 \mathrm{~S}+1)-1=4 \mu_{\mathrm{B}}$. Comparing this magnetic moment to that of bulk Fe $\left(2.2 \mu_{\mathrm{B}}\right),{ }^{54-56}$ and atomic $\mathrm{Fe}\left(4 \mu_{\mathrm{B}}\right),{ }^{57,58}$ we see that an iron atom retains its high atomic spin when it interacts with a single pyrene molecule, just as it did when it interacted with a single coronene. ${ }^{42}$ On the contrary, while interacting with a benzene molecule, ${ }^{12,17,18}$ the spin magnetic moment of iron atom decreases to $2 \mu_{\mathrm{B}}$.

Interestingly, the coordination between an iron atom and a pyrene molecule differs from that of $\mathrm{Fe}_{1}$ (coronene) ${ }_{1}$ and its anion, where an iron atom can also bind with $\eta^{6}$-coordination to coronene. ${ }^{42}$ We also know from our earlier work ${ }^{12}$ that $\left[\mathrm{Fe}_{1} \text { (benzene) }\right]^{-}$prefers a $\mathrm{C}_{6 \mathrm{v}}$ symmetric structure with the iron atom on top of the benzene ring. Moreover, while the measured $\mathrm{EA}$ values of $\mathrm{Fe}_{1}$ (benzene) $)_{1}$ and $\mathrm{Fe}_{1}$ (coronene) $)_{1}$ are $0.46 \mathrm{eV}^{12}$ and $1.06 \mathrm{eV}$, respectively, at $0.91 \mathrm{eV}$, the EA value of $\mathrm{Fe}_{1}$ (pyrene) $)_{1}$ lies between them, albeit somewhat closer to that of $\mathrm{Fe}_{1}$ (coronene) $)_{1}$. It is also important to note that the photoelectron spectral profiles of these three anionic complexes are quite different from one another. Thus, each of these $\left.\left[\mathrm{Fe}_{1} \text { (aromatic hydrocarbon) }\right)_{1}\right]^{-}$anionic complexes has its own set of interactions between the iron atom and its organic ligand. Furthermore, it is clear that none of these three are anion-neutral (solvated anion) complexes. Their photoelectron spectra show no significant resemblance to that of atomic $\mathrm{Fe}^{-} .59$

\section{$\mathrm{Fe}_{2}$ (pyrene $)_{1}$ and $\left[\mathrm{Fe}_{2}(\text { pyrene })_{1}\right]^{-}$}

Unlike the photoelectron spectra of $\left[\mathrm{Fe}_{1} \text { (benzene) }\right]^{-}$, $\left[\mathrm{Fe}_{1} \text { (pyrene) }\right]^{-}$, and $\left.\left[\mathrm{Fe}_{1} \text { (coronene }\right)_{1}\right]^{-}$, the photoelectron spectra of $\left.\left.\left[\mathrm{Fe}_{2} \text { (benzene) }\right)_{1}\right]^{-12}\left[\mathrm{Fe}_{2} \text { (pyrene) }\right)_{1}\right]^{-}$, and $\left[\mathrm{Fe}_{2} \text { (coronene) }\right]^{-42}$ exhibit almost identical spectral profiles, differing only by their shifted locations along the EBE scale. Since their photoelectron spectral profiles are quite different from that of $\mathrm{Fe}_{2}{ }^{-}$, they are not $\mathrm{Fe}_{2}{ }^{-}$(aromatic hydrocarbon) solvated dimer anion complexes. Nevertheless, their similar profiles strongly suggest that they share common structural and electronic characteristics. Furthermore, while the measured $\mathrm{EA}$ values of $\mathrm{Fe}_{2}$ (benzene) $)_{1}$ and $\mathrm{Fe}_{2}$ (coronene) $)_{1}$ are $1.15 \mathrm{eV}^{12}$ and $1.59 \mathrm{eV},{ }^{42}$ respectively, at $1.50 \mathrm{eV}$, the EA value of $\mathrm{Fe}_{2}$ (pyrene) $)_{1}$ lies between them, again somewhat closer to that of $\mathrm{Fe}_{2}$ (coronene) $)_{1}$. The VDE value for $\left[\mathrm{Fe}_{2} \text { (pyrene) }\right]^{-}$is $1.62 \mathrm{eV}$. The prominent sharp peak in its photoelectron spectrum is located at $\mathrm{EBE}=2.86 \mathrm{eV}$. Their photoelectron spectra show no significant resemblance to that of $\mathrm{Fe}_{2}{ }^{-} .60$

Our calculations found that $\left.\left[\mathrm{Fe}_{2} \text { (pyrene }\right)_{1}\right]^{-}$and its neutral counterpart prefer structures where the iron atoms dimerize and bind perpendicularly to the plane of the pyrene molecule (See Figure 3). These geometries are similar to the structures we found for $\left.\left[\mathrm{Fe}_{2} \text { (coronene) }\right)_{1}\right]^{-42}$ and $\left.\left[\mathrm{Co}_{2} \text { (pyrene }\right)_{1}\right]^{-49}$ clusters. The lowest energy isomer 


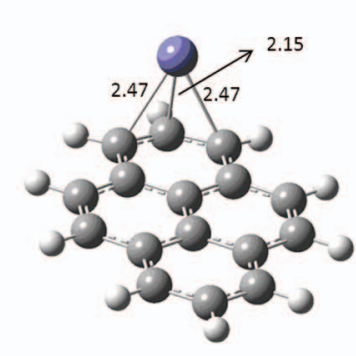

Isomer- $1: \Delta \mathrm{E}=\mathbf{0 . 0 0} \mathrm{eV}$ $2 S+1=4$
ANION

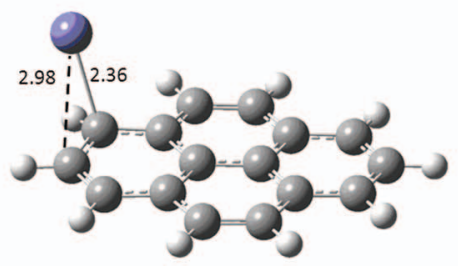

Isomer-2: $\Delta \mathrm{E}=\mathbf{0 . 0 7} \mathrm{eV}$ $2 S+1=4$

NEUTRAL
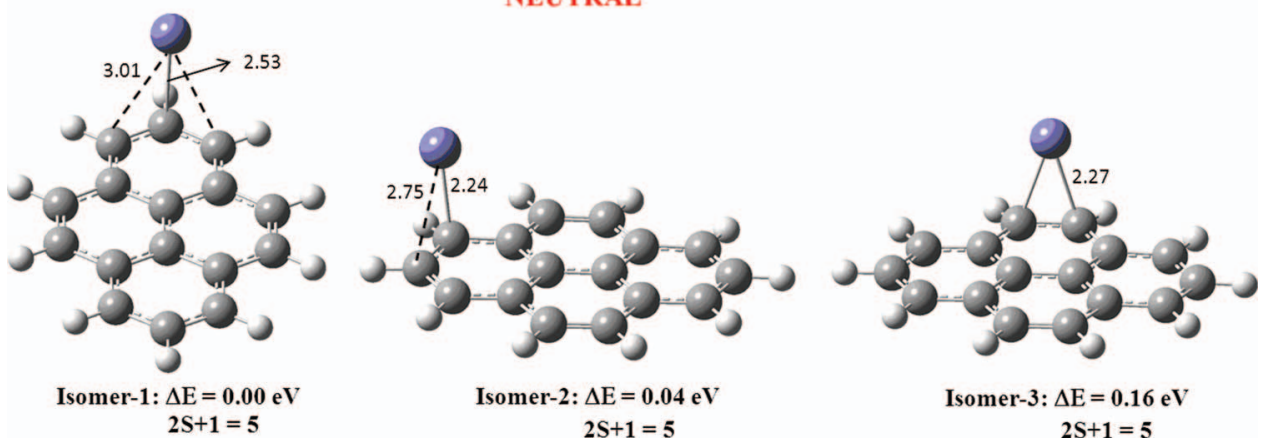

FIG. 2. The calculated most stable structures of anionic and neutral $\mathrm{Fe}_{1}$ (pyrene) $)_{1}$. The spin multiplicities and the relative energies in eV are also shown.

(Isomer-1) of $\left.\left[\mathrm{Fe}_{2} \text { (pyrene) }\right)_{1}\right]^{-}$cluster can be seen as an extension of the higher energy of neutral $\mathrm{Fe}_{1}$ (pyrene) $)_{1}$ cluster (Isomer-3 in Figure 2). While, the higher energy isomer $(\Delta \mathrm{E}$ $=0.27 \mathrm{eV}$ ) is an extension of the lowest energy isomer of $\left.\left[\mathrm{Fe}_{1} \text { (pyrene }\right)_{1}\right]^{-}$cluster, where the second iron atom binds to the first metal atom, rather than the pyrene molecule. Both the isomers of anionic $\mathrm{Fe}_{2}$ (pyrene) $)_{1}$ cluster prefer a sextet

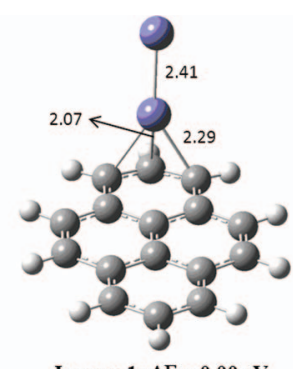

Isomer-1: $\Delta \mathrm{E}=\mathbf{0 . 0 0} \mathrm{eV}$ $2 S+1=6$
ANION

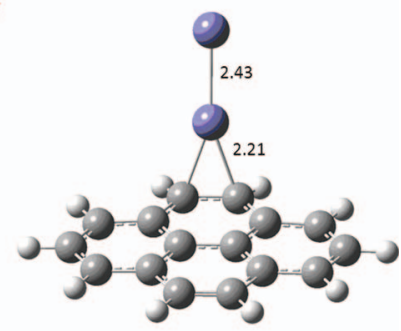

Isomer-2: $\Delta \mathrm{E}=\mathbf{0 . 2 7} \mathrm{eV}$ $2 \mathrm{~S}+1=6$

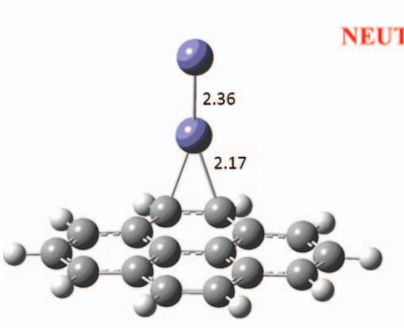

Isomer-1: $\Delta \mathrm{E}=\mathbf{0 . 0 0} \mathrm{eV}$ $2 \mathrm{~S}+1=7$

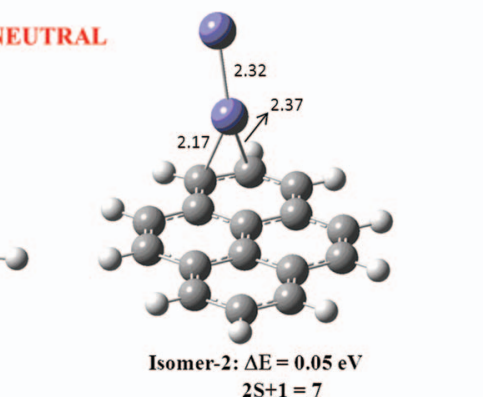

FIG. 3. The calculated most stable structures of anionic and neutral $\mathrm{Fe}_{2}$ (pyrene) $)_{1}$. The spin multiplicities and the relative energies in $\mathrm{eV}$ are also shown. spin state $(2 \mathrm{~S}+1=6)$. Note that the $\left.\left[\mathrm{Fe}_{2} \text { (coronene) }\right)_{1}\right]^{-}$ cluster, reported earlier, ${ }^{42}$ also prefers a spin multiplicity of sextet.

The calculated electron vertical detachment energies of the lowest energy isomer (Isomer-1) are $1.42 \mathrm{eV}$ (from anionic sextet to neutral septet) and $2.01 \mathrm{eV}$ (from anionic sextet to neutral quintet); while the corresponding vertical detachment energies of Isomer-2 are $1.30 \mathrm{eV}$ (anionic sextet to neutral septet) and $2.36 \mathrm{eV}$ (sextet to quintet). Thus, only the calculated VDE of Isomer-1 is in decent agreement with the measured value of $1.60 \mathrm{eV}$. In order to verify if the lowest energy isomer (Isomer-1) can explain all the peaks in the observed photoelectron spectrum, we calculated the electron detachment energies corresponding to the transitions from the anionic ground state (septet) to the ground state and the excited states of neutral septet and neutral quintet states of Isomer-1. These values are marked as sticks in the Figure 1. The calculated VDE $(1.42 \mathrm{eV})$ of the $\left[\mathrm{Fe}_{2}(\text { pyrene })_{1}\right]^{-}$cluster corresponds to the electron detachment from the $\beta$-MO $\left(\beta-67 \mathrm{a}^{\prime \prime}\right)$ of the anion, resulting in a septet neutral state. The next four transition energies in the photoelectron spectrum correspond to electron detachment from $\beta$-MOs $\left(\beta-66 \mathrm{a}^{\prime}, \beta\right.$ $65 \mathrm{a}^{\prime \prime}, \beta-64 \mathrm{a}^{\prime}$, and $\left.\beta-63 \mathrm{a}^{\prime \prime}\right)$, whose energies are calculated to be $1.66,1.67,1.72$, and $1.90 \mathrm{eV}$, respectively (See Figure 1). The first electron detachment from an $\alpha-\mathrm{MO}\left(\alpha-72 \mathrm{a}^{\prime}\right)$ of Isomer-1, resulting in a neutral quintet state, corresponds to vertical detachment energy of $2.01 \mathrm{eV}$. The next four transition energies in the photoelectron spectrum correspond to electron detachment from $\alpha$-MOs, resulting in excited neutral quintet. The calculated vertical detachment energies for these transitions are: $2.15 \mathrm{eV}$ (from $\alpha-71 \mathrm{a}^{\prime}$ ), $2.40 \mathrm{eV}$ (from $\alpha$ $\left.70 \mathrm{a}^{\prime \prime}\right), 2.45 \mathrm{eV}$ (from $\left.\alpha-69 \mathrm{a}^{\prime}\right)$, and $2.47 \mathrm{eV}\left(\right.$ from $\left.\alpha-68 \mathrm{a}^{\prime \prime}\right)$. The 
prominent sharp peak in the photoelectron spectrum (EBE $=2.86 \mathrm{eV}$ ) corresponds to the electron detachment from $\alpha$-MO $\left(\alpha-67 \mathrm{a}^{\prime}\right)$, with the calculated transition energy of $2.77 \mathrm{eV}$, while the broad peak at $\mathrm{EBE}=3.2 \mathrm{eV}$ corresponds to the electron detachment from $\alpha-66 \mathrm{a}^{\prime \prime}$, with calculated detachment energy of $3.23 \mathrm{eV}$ (See Figure 1). Based on the agreement between the calculated electron detachment energies of Isomer-1 and the experimental photodetachment energies, we conclude that Isomer-1 is the ground sate geometry of $\left.\left[\mathrm{Fe}_{2} \text { (pyrene }\right)_{1}\right]^{-}$cluster.

The ground state structure of neutral $\mathrm{Fe}_{2}$ (pyrene) ${ }_{1}$ cluster is similar to that of its anionic counterpart, while another isomer which is iso-energetic $(\Delta \mathrm{E}=0.05 \mathrm{eV})$ with the ground state structure is similar to the higher energy isomer of $\left.\left[\mathrm{Fe}_{2} \text { (pyrene }\right)_{1}\right]^{-}$. Both these isomers prefer a septet spin state $(2 S+1=7)$, and thus a spin magnetic moment is $6 \mu_{\mathrm{B}}$. Since there are two $\mathrm{Fe}$ atoms in the cluster, the per atom magnetic moment is $6 / 2=3 \mu_{\mathrm{B}}$. Comparing this value to that of $\mathrm{Fe}_{2}$, i.e., $3 \mu_{\mathrm{B}}$ per atom, ${ }^{59}$ we note that again the high spin magnetic moment of the iron moiety is retained when it interacts with a pyrene molecule. A similar scenario was observed ${ }^{42}$ for $\mathrm{Fe}_{2}$ (coronene) cluster as well. The quintet $(2 \mathrm{~S}+1=5)$ spin state of the ground state isomer is found to be $0.98 \mathrm{eV}$ higher in energy than the septet spin state.

\section{$\mathrm{Fe}_{1}(\text { pyrene })_{2}$ and $\left[\mathrm{Fe}_{1}(\text { pyrene })_{2}\right]^{-}$}

The photoelectron spectra of $\left.\left[\mathrm{Fe}_{1} \text { (pyrene }\right)_{2}\right]^{-}$, $\left[\mathrm{Fe}_{1}(\text { coronene })_{2}\right]^{-}$, and $\left.\left[\mathrm{Fe}_{1} \text { (benzene }\right)_{2}\right]^{-}$all exhibit similar spectral profiles which are shifted relative to one another. All of them have a narrow, relatively weak intensity peak on their low EBE side with a broad band at higher EBE. The onset of the $\left.\left[\mathrm{Fe}_{1} \text { (pyrene) }\right)_{2}\right]^{-}$spectrum occurs at EBE
$=1.40 \mathrm{eV}$, which is taken to be the EA of neutral $\mathrm{Fe}_{1}$ (pyrene) $)_{2}$. The first peak in the spectrum is centered at $\mathrm{EBE}=1.51 \mathrm{eV}$, and this is its $\mathrm{VDE}$ value, while the next peak is centered at $\mathrm{EBE}=2.25 \mathrm{eV}$. The $\mathrm{EA}$ values of neutral $\mathrm{Fe}_{1}$ (benzene) $)_{2}$ and $\mathrm{Fe}_{1}$ (coronene) $)_{2}$ are $0.78 \mathrm{eV}^{12}$ and $1.50 \mathrm{eV}^{42}$ respectively. Thus, at $1.40 \mathrm{eV}$, the EA of $\mathrm{Fe}_{1}$ (pyrene $)_{2}$ again lies in between these two, albeit closer to $\mathrm{Fe}_{2}$ (coronene) $)_{1}$.

Our calculations found that the most stable structures of both neutral and anionic $\mathrm{Fe}_{1}$ (pyrene) $)_{2}$ clusters are similar to those of neutral and anionic $\mathrm{Fe}_{1}$ (coronene) $)_{2}$ clusters, where a staggered (step-like) sandwich structure (symmetry: $\mathrm{C}_{\mathrm{i}}$ ) is preferred. In this kind of structure, the iron atom is sandwiched between the two pyrene molecules and the two pyrene planes are shifted away from each other (see Figure 4). However, while the iron atom binds to $\eta^{2}$-bridge sites on the terminal rings of $\mathrm{Fe}_{1}$ (coronene) $)_{2}$ complexes, it binds to $\eta^{3}$-bridge sites in $\mathrm{Fe}_{1}$ (pyrene) $)_{2}$ complexes. The slightly different structures found in the $\mathrm{Fe}_{1}$ (pyrene $)_{2}$ vs. the $\mathrm{Fe}_{1}$ (coronene) $)_{2}$ systems may be due to coronene and pyrene positioning themselves so as to minimize the repulsion between the $\pi$-electrons of their rings. This would not be expected in the $\mathrm{Fe}_{1}$ (benzene) 2 system, since benzene is a single ring carbon network and the sandwiching of the metal atom between the benzene rings minimizes the interaction between the rings. In the case of $\left.\left[\mathrm{Fe}_{1} \text { (pyrene }\right)_{2}\right]^{-}$cluster the normal sandwich structure (Isomer-2) is found to be $0.29 \mathrm{eV}$ higher in energy than the staggered sandwich structure. Both these isomers prefer a doublet spin multiplicity $(2 S+1=2)$. In the case of the lowest energy staggered sandwich structure, the quartet (2S $+1=4)$ spin state was found to be $0.23 \mathrm{eV}$ higher in energy, while the sextet $(2 \mathrm{~S}+1=6)$ spin state is $0.47 \mathrm{eV}$ higher in
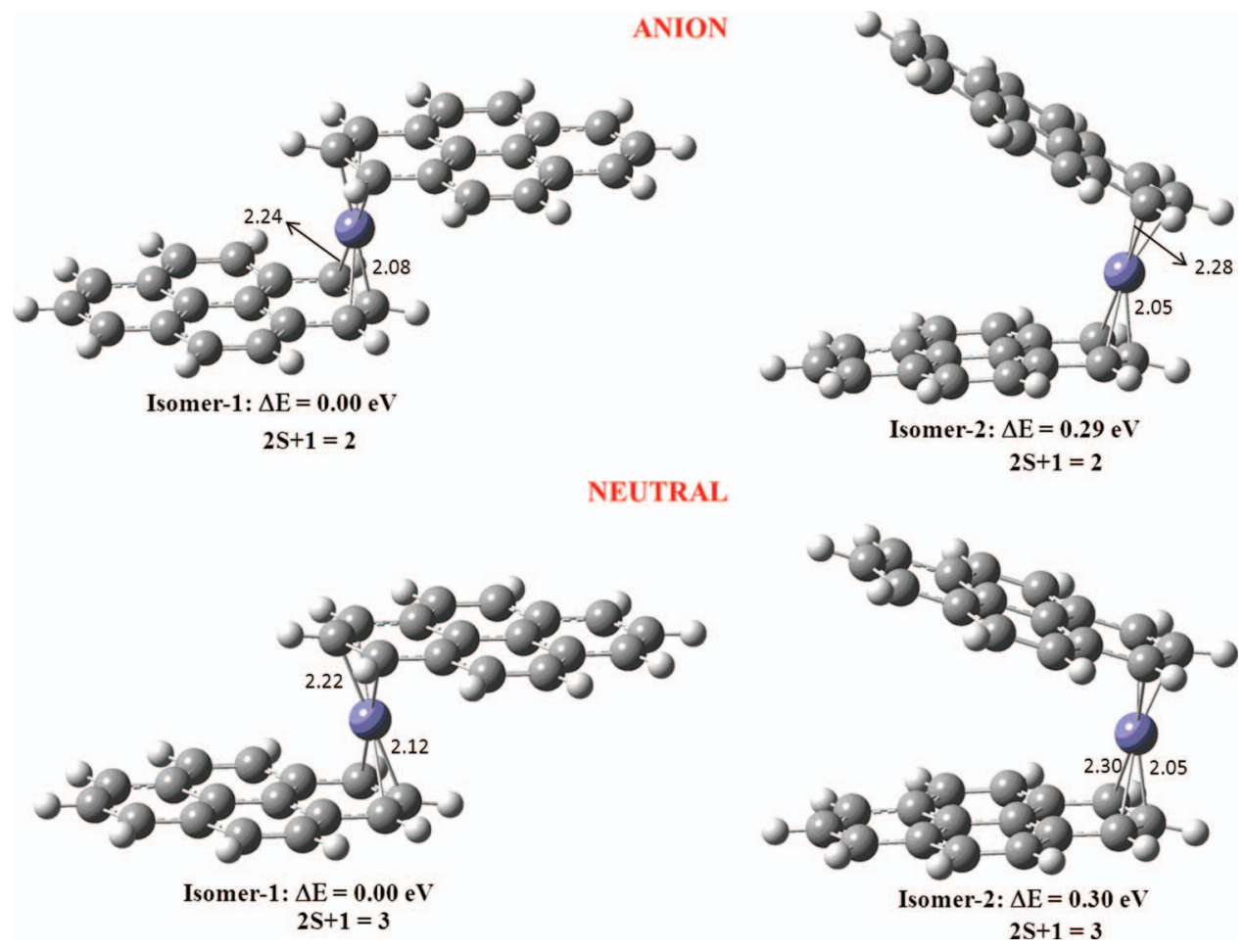

FIG. 4. The calculated most stable structures of anionic and neutral $\mathrm{Fe}_{1}$ (pyrene) 2 . The spin multiplicities and the relative energies in eV are also shown. 
energy than the doublet spin state. The calculated VDE values for Isomer-1, the lowest energy structure of $\left.\left[\mathrm{Fe}_{1} \text { (pyrene }\right)_{2}\right]^{-}$, are $1.40 \mathrm{eV}$ (anion doublet to neutral triplet) and $3.08 \mathrm{eV}$ (anion doublet to neutral singlet). Thus, the calculated VDE of $1.40 \mathrm{eV}$ is in good agreement with the measured value of $1.51 \mathrm{eV}$. Furthermore, the calculated VDE value of Isomer$2,1.84 \mathrm{eV}$, is due to the electron detachment from $\beta$-MO.

As mentioned above, the lowest energy geometry of neutral $\mathrm{Fe}_{1}$ (pyrene) $)_{2}$ cluster is also a staggered sandwich structure, with the normal sandwich geometry being $0.30 \mathrm{eV}$ higher in energy (See Figure 4). In our earlier study ${ }^{49}$ on Co(pyrene) clusters also, the staggered sandwich structure was found to be the lowest energy structure for $\mathrm{Co}_{1}$ (pyrene $)_{2}$ cluster. Both the staggered sandwich and normal sandwich structures prefer triplet multiplicity $(2 \mathrm{~S}+1=3)$. The EA of the $\mathrm{Fe}_{1}$ (pyrene) $)_{2}$ cluster is calculated to be $1.24 \mathrm{eV}$ and is in agreement with the experimental value of $1.40 \mathrm{eV}$. As the calculated spin multiplicity of the neutral $\mathrm{Fe}_{1}$ (pyrene) $)_{2}$ cluster is $2 \mathrm{~S}+1=3$; it results in a spin magnetic moment of $2 \mu_{\mathrm{B}}$ for the cluster. It indicates that although the iron atom retains its atomic spin moment of $4 \mu_{\mathrm{B}}$ while interacting with a single pyrene molecule, when it interacts with two pyrene molecules, its spin magnetic moment is reduced, moving closer to the bulk value of $2.2 \mu_{\mathrm{B}}$. Similar results were seen in the case of iron-coronene systems.

\section{$\mathrm{Fe}_{2}(\text { pyrene })_{2}$ and $\left[\mathrm{Fe}_{2}(\text { pyrene })_{2}\right]^{-}$}

The photoelectron spectrum of $\left.\left[\mathrm{Fe}_{2} \text { (pyrene }\right)_{2}\right]^{-}$exhibits a broad band or mixture of bands which resembles a broad- ened version of the $\left.\left[\mathrm{Fe}_{2} \text { (benzene }\right)_{2}\right]^{-}$spectrum. The EA of neutral $\mathrm{Fe}_{2}$ (pyrene) $)_{2}$ is estimated to be $1.33 \mathrm{eV}$, while the $\mathrm{VDE}$ is $\sim 1.6 \mathrm{eV}$. A comparable photoelectron spectrum was observed for $\left.\left[\mathrm{Fe}_{2} \text { (coronene) }\right)_{2}\right]^{-} .^{42}$ Our calculations reveal the existence of two iso-energetic $(\Delta \mathrm{E}=0.04 \mathrm{eV})$ structures for $\left.\left[\mathrm{Fe}_{2} \text { (pyrene }\right)_{2}\right]^{-}$cluster: a regular/normal sandwich structure (Isomer-1, Figure 5) and a staggered sandwich structure (Isomer-2, Figure 5). In both of these isomers, the iron atoms are sandwiched by and parallel to the pyrene molecules. In both of these isomers, the distance between the two iron atoms is too large (2.56 $\AA$ in Isomer-1, $2.79 \AA$ in Isomer-2) to have a bond between the metal atoms. However, in both cases, the metal atoms bind only to the edges of the pyrene ring with $\eta^{2}$ coordination to a given pyrene molecule. Interestingly, while the lowest energy isomer (Isomer-1) prefers a spin multiplicity of sextet $(2 S+1=6)$, the staggered sandwich (Isomer$2)$ is in a quartet spin state $(2 S+1=4)$. The quartet spin state of Isomer- 1 is $0.53 \mathrm{eV}$ higher in energy than the sextet spin state, while in the case of Isomer-2, the sextet spin state is $0.20 \mathrm{eV}$ higher in energy than the quartet spin state. Thus, in the case of staggered sandwich structure (Isomer2), there is a competition between the sextet and quartet spin states in stabilizing the system. The two lowest energy sandwich structures are similar to the lowest energy isomers of $\left.\left[\mathrm{Fe}_{2} \text { (coronene }\right)_{2}\right]^{-}$clusters $^{42}$ and $\left[\mathrm{Co}_{2}(\text { pyrene })_{2}\right]^{-}$clusters, ${ }^{49}$ reported earlier. However, in the case of $\left.\left[\mathrm{Fe}_{2} \text { (coronene }\right)_{2}\right]^{-}$ cluster, the most preferred spin state was reported to be a quartet $(2 S+1=4)$, irrespective of the nature of sandwich (staggered vs. normal).

The calculated electron detachment energies of the lowest energy isomer (Isomer-1) are $1.62 \mathrm{eV}$ (transition from

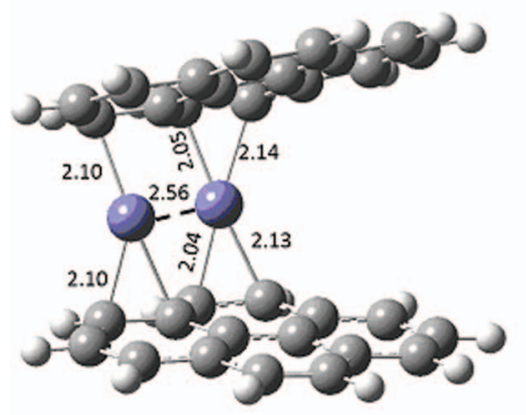

Isomer-1: $\Delta \mathrm{E}=\mathbf{0 . 0 0} \mathrm{eV}$ $2 S+1=6$

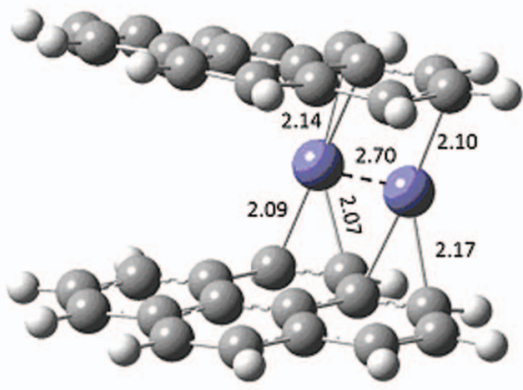

Isomer-1: $\Delta \mathrm{E}=0.00 \mathrm{eV}$ $2 \mathrm{~S}+1=5$

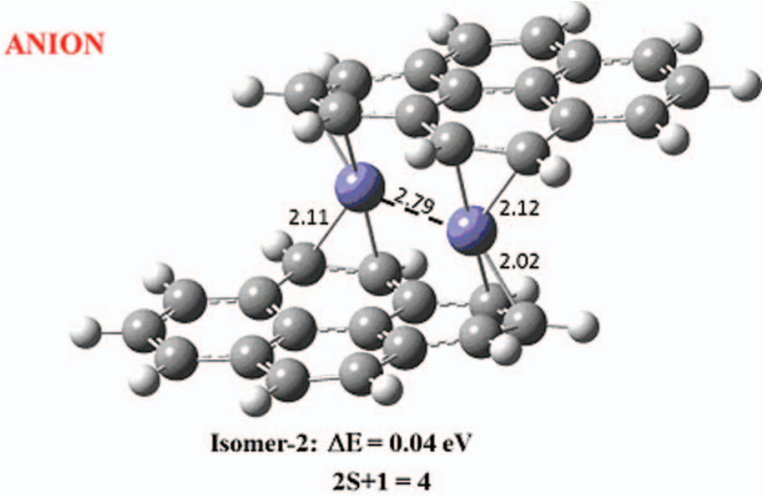

NEUTRAL

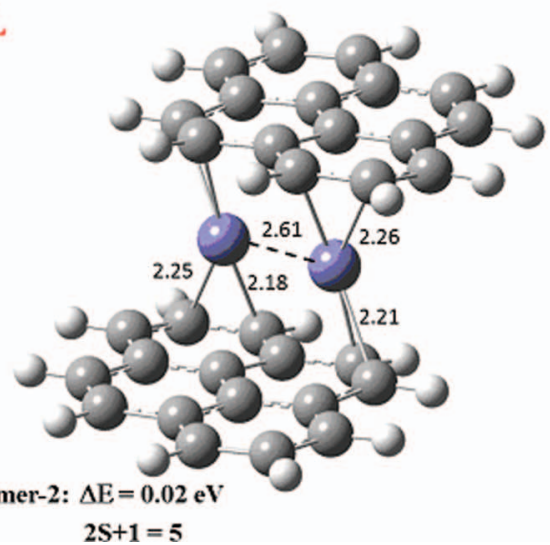

FIG. 5. The calculated most stable structures of anionic and neutral $\mathrm{Fe}_{2}$ (pyrene) $)_{2}$. The spin multiplicities and the relative energies in eV are also shown. 
anion sextet to neutral quintet) and $1.83 \mathrm{eV}$ (anion sextet to neutral septet). For Isomer-2, the calculated electron detachment energies are $1.40 \mathrm{eV}$ and $2.00 \mathrm{eV}$, corresponding to the transition from anion quartet to neutral quintet and neutral triplet states, respectively. Our calculated VDE for Isomer1 is in excellent agreement with the measured VDE value. However, one cannot rule out the contribution from the higher energy isomer (Isomer-2) towards the observed spectrum. As can be observed from the photoelectron spectrum, there are no distinct peaks observed for this cluster. In order to understand the spectrum further and to verify if Isomer-2 is also contributing towards the observed spectrum, we have calculated the electron detachment energies corresponding to transitions from the anionic ground state to the excited states of neutral cluster for both isomers and are shown as sticks in Figure 1, with red sticks for Isomer-1 and blue sticks for Isomer-2. In the case of Isomer-1, transitions leading to excited state neutral quintet are given in smaller red sticks (at $1.62 \mathrm{eV}$ ), while the transitions to excited septet are given in longer red sticks (at 2.51, 2.6, 2.73, 2.97, and $3.05 \mathrm{eV}$ ). For Isomer-2, the transitions to excited neutral quintet are given by shorter blue sticks (at 2.41, 2.51, 2.84, and $3.03 \mathrm{eV}$ ), while the transitions leading to excited neutral triplet are shown by longer blue sticks (at 2.32, 2.43, 2.89, 2.98, and $3.03 \mathrm{eV}$ ). As can be observed from Figure 1, both the regular and staggered sandwich structures are contributing towards the observed spectrum of $\left[\mathrm{Fe}_{2}(\text { pyrene })_{2}\right]^{-}$cluster.

The two lowest energy geometries of neutral $\mathrm{Fe}_{2}$ (pyrene) $)_{2}$ cluster, given in Figure 5, are similar to their anionic counterparts, with the normal sandwich structure being lower in energy by $0.02 \mathrm{eV}$ than the staggered sandwich structure. Given the negligible energy difference between these isomers, we cannot identify the ground state geometry of this cluster. Perhaps, both these isomers are equally probable. A similar scenario was observed for $\mathrm{Fe}_{2}$ (coronene $)_{2}$ and $\mathrm{Co}_{2}$ (pyrene) $)_{2}$ clusters where the staggered and normal sandwich structures were iso-energetic. Both of these isomers prefer a quintet $(2 S+1=5)$ spin state, leading to a total spin magnetic moment of $4 \mu_{\mathrm{B}}$ for $\mathrm{Fe}_{2}$ (pyrene $)_{2}$ cluster, with each iron atom with a spin moment of $2 \mu_{\mathrm{B}}$. Note that the spin magnetic moment of $\mathrm{Fe}_{2}$ (pyrene) $)_{1}$ cluster is $6 \mu_{\mathrm{B}}\left(3 \mu_{\mathrm{B}}\right.$ per iron atom), thus the second pyrene molecule reduces the spin magnetic moment on the $\mathrm{Fe}$ atoms. On the other hand, the spin magnetic moment, $4 \mu_{\mathrm{B}}$, of $\mathrm{Fe}_{2}$ (coronene) $)_{2}$ indicates that pyrene and coronene molecules have the same effect on the spin magnetic moments of $\mathrm{Fe}_{2}$ dimer. However, when compared to the spin magnetic moment of $\mathrm{Fe}_{2}$ molecule ( $3 \mu_{\mathrm{B}}$ per atom), pyrene molecules reduce the spin magnetic moment of iron atoms towards the bulk value of $2.2 \mu_{\mathrm{B}}$. In the case of Isomer-1, the septet spin state is $0.45 \mathrm{eV}$ higher in energy than the quintet state, while in the case of Isomer-2, the triplet state is $0.67 \mathrm{eV}$ higher in energy than the quintet state.

\section{SUMMARY}

Comparison of the observed trends shows that EA and VDE values for iron-pyrene clusters (Table II) more closely resemble those of iron-coronene clusters than for those of iron-benzene clusters. This same conclusion is reached by examining the calculated structures. Pyrene exhibits behavior which is intermediate between those of benzene and coronene in both neutral and anionic complexes with iron atoms and dimers. The reasonable agreement between the calculated and measured electron detachment energies not only validates the accuracy of the theoretical procedure, but also lends credence to the predicted structures and their corresponding spin magnetic moments. The calculations reveal the ability of an iron atom or an iron dimer to retain their high spin magnetic moments when interacting with pyrene molecule, similar to that observed for coronene.

\section{ACKNOWLEDGMENTS}

This material is based upon work supported by the Division of Materials Science and Engineering, Basic Energy Sciences, (U.S.) Department of Energy, under Grant No. DEFG02-09ER46558 (KHB). P.J. also thanks Department of Energy for partial support. A.K.K. acknowledges the faculty start-up funds made available through the Louisiana Board of Regents-Research Commercialization/Educational Enhancement Program (RC/EEP).

${ }^{1}$ K. Hoshino, T. Kurikawa, H. Takeda, A. Nakajima, and K. Kaya, J. Phys. Chem. 99, 3053 (1995).

${ }^{2}$ M. Hirano, K. Judai, A. Nakajima, and K. Kaya, J. Phys. Chem. A 101, 4893 (1997).

${ }^{3}$ K. Judai, M. Hirano, H. Kawamata, S. Yabushita, A. Nakajima, and K. Kaya, Chem. Phys. Lett. 270, 23 (1997).

${ }^{4}$ T. Kurikawa, H. Takeda, A. Nakajima, and K. Kaya, Z. Phys. D: At., Mol. Clusters 40, 65 (1997).

${ }^{5}$ T. Kurikawa, H. Takeda, M. Hirano, K. Judai, T. Arita, S. Nagao, A. Nakajima, and K. Kaya, Organometallics 18, 1430 (1999).

${ }^{6}$ A. Nakajima and K. Kaya, J. Phys. Chem. A 104, 176 (2000).

${ }^{7}$ M. B. Knickelbein, J. Chem. Phys. 125, 044308 (2006).

${ }^{8}$ K. Miyajima, S. Yabushita, M. B. Knickelbein, and A. Nakajima, J. Am. Chem. Soc. 129, 8473 (2007).

${ }^{9}$ M. Gerhards, O. C. Thomas, J. M. Nilles, W.-J. Zheng, and K. H. Bowen, J. Chem. Phys. 116, 10247 (2002).

${ }^{10}$ W.-J. Zheng, J. M. Nilles, O. C. Thomas, and K. H. Bowen, J. Chem. Phys. 122, 044306 (2005).

${ }^{11}$ W.-J. Zheng, J. M. Nilles, O. C. Thomas, and K. H. Bowen, Chem. Phys. Lett. 401, 266 (2005).

${ }^{12}$ W.-J. Zheng, S. N. Eustis, X. Li, J. M. Nilles, O. C. Thomas, K. H. Bowen, and A. K. Kandalam, Chem. Phys. Lett. 462, 35 (2008).

${ }^{13}$ K. F. Willey, P. Y. Cheng, M. B. Bishop, and M. A. Duncan, J. Am. Chem. Soc. 113, 4721 (1991).

${ }^{14}$ K. F. Willey, C. S. Yeh, D. L. Robbins, and M. A. Duncan, J. Phys. Chem. 96, 9106 (1992).

${ }^{15}$ J. W. Buchanan, G. A. Grieves, J. E. Reddic, and M. A. Duncan, Int. J. Mass. Spectrom. 182 and 183, 323 (1999).

${ }^{16}$ T. D. Jaeger and M. A. Duncan, Int. J. Mass. Spectrom. 241, 165 (2005).

${ }^{17}$ R. Pandey, B. K. Rao, P. Jena, and J. M. Newsam, Chem. Phys. Lett. 321,142 (2000).

${ }^{18}$ R. Pandey, B. K. Rao, P. Jena, and M. A. Blanco, J. Am. Chem. Soc. 123, 3799 (2001)

${ }^{19}$ B. K. Rao and P. Jena, J. Chem. Phys. 116, 1343 (2002).

${ }^{20}$ B. K. Rao and P. Jena, J. Chem. Phys. 117, 5234 (2002).

${ }^{21}$ A. K. Kandalam, B. K. Rao, P. Jena, and R. Pandey, J. Chem. Phys. 120, 10414 (2004).

${ }^{22}$ B. D. Edmonds, A. K. Kandalam, S. N. Khanna, X. Li, A. Grubisic, I. Khanna, and K. H. Bowen, J. Chem. Phys. 124, 074316 (2006).

${ }^{23}$ F. Tast, N. Malinowski, S. Frank, M. Heinebrodt, I. M. L. Billas, and T. P. Martin, Z. Phys. D: At., Mol. Clusters 40, 351 (1997).

${ }^{24}$ F. Tast, N. Malinowski, S. Frank, M. Heinebrodt, I. M. L. Billas, and T. P. Martin, Phys. Rev. Lett. 77, 3529 (1996). 
${ }^{25}$ W. Branz, I. M. L. Billas, N. Malinowski, F. Tast, M. Heinebrodt, and T. P. Martin, J. Chem. Phys. 109, 3425 (1998).

${ }^{26}$ Y. Basir and S. L. Anderson, Chem. Phys. Lett. 243, 45 (1995).

${ }^{27}$ A. Nakajima, S. Nagao, H. Takeda, T. Kurikawa, and K. Kaya, J. Chem. Phys. 107, 6491 (1997).

${ }^{28}$ T. Kurikawa, S. Nagao, K. Miyajima, A. Nakajima, and K. Kaya, J. Phys. Chem. A 102, 1743 (1998).

${ }^{29}$ S. Nagao, T. Kurikawa, K. Miyajima, A. Nakajima, and K. Kaya, J. Phys. Chem. A 102, 4495 (1998).

${ }^{30}$ J. E. Reddic, J. C. Robinson, and M. A. Duncan, Chem. Phys. Lett. 279, 203 (1997).

${ }^{31}$ G. A. Grievesa, J. W. Buchanana, J. E. Reddic, and M. A. Duncan, Int. J. Mass. Spectrom. 204, 223 (2001).

${ }^{32}$ B. P. Pozniak and R. C. Dunbar, J. Am. Chem. Soc. 119, 10439 (1997).

${ }^{33}$ J. W. Buchanan, J. E. Reddic, G. A. Grieves, and M. A. Duncan, J. Phys. Chem. A 102, 6390 (1998).

${ }^{34}$ N. R. Foster, G. A. Grieves, J. W. Buchanan, N. D. Flynn, and M. A. Duncan, J. Phys. Chem. A 104, 11055 (2000).

${ }^{35}$ M. A. Duncan, A. M. Knight, Y. Negishi, S. Nagao, K. Judai, A. Nakajima, and K. Kaya, J. Phys. Chem. A 105, 10093 (2001).

${ }^{36}$ T. M. Ayers, B. C. Westlake, and M. A. Duncan, J. Phys. Chem. A 108, 9805 (2004).

${ }^{37}$ N. R. Foster, J. W. Buchanan, N. D. Flynn, and M. A. Duncan, Chem. Phys. Lett. 341, 476 (2001).

${ }^{38}$ J. W. Buchanan, G. A. Grieves, N. D. Flynn, and M. A. Duncan, Int. J. Mass. Spectrom. 185, 617 (1999).

${ }^{39}$ A. C. Scott, J. W. Buchanan, N. D. Flynn, and M. A. Duncan, Int. J. Mass. Spectrom. 269, 55 (2008).

${ }^{40}$ A. Klotz, P. Marty, P. Boissel, D. de Caro, G. Serra, J. Mascetti, P. de Parseval, J. Derouault, J.-P. Daudey, and B. Chaudret, Planet. Space Sci. 44, 957 (1996).
${ }^{41}$ A. K. Kandalam, B. Kiran, P. Jena, X. Li, A. Grubisic, and K. H. Bowen. J. Chem. Phys. 126, 084306 (2007).

${ }^{42}$ X. Li, S. N. Eustis, K. H. Bowen, A. K. Kandalam, and P. Jena, J. Chem. Phys. 129, 074313 (2008).

${ }^{43}$ T. D. Jaeger and M. A. Duncan, J. Phys. Chem. A 108, 11296 (2004).

${ }^{44}$ X. Li, S. N. Eustis, K. H. Bowen, and A. K. Kandalam, J. Chem. Phys. 129, 124312 (2008).

${ }^{45}$ M. Munakata, L. P. Wu, T. Kuroda-Sowa, M. Maekawa, Y. Suenaga, and K. Sugimoto, Inorg. Chem. 36, 4903 (1997).

${ }^{46}$ A. C. Scott, J. W. Buchanan, N. D. Flynn, and M. A. Duncan, Int. J. Mass. Spectrom. 266, 149 (2007).

${ }^{47}$ I. M. L. Billas, A. Châtelain, and W. A. de Heer, Science 2651682 (1994).

${ }^{48}$ G. Serra, B. Chaudret, Y. Saillard, A. L. Beuze, H. Rabaa, I. Ristorcelli, and A. Klotz, Astron. Astrophys. 260, 489 (1992).

${ }^{49}$ A. K. Kandalam, P. Jena, X. Li, S. N. Eustis, and K. H. Bowen, J. Chem. Phys. 129, 134308 (2008).

${ }^{50}$ M. J. Frisch, G. W. Trucks, H. B. Schlegel et al., GAUSSiAn 03, Revision C.02, Gaussian, Inc., Wallingford, CT, 2004

${ }^{51}$ A. D. Becke, J. Chem. Phys. 98, 5648 (1993).

${ }^{52}$ C. Lee, W. Yang, and R. G. Parr, Phys. Rev. B 37, 785 (1988).

${ }^{53}$ A. Simon and C. Joblin, J. Phys. Chem. A 111, 9745 (2007)

${ }^{54}$ N. W. Ashcroft and N. D. Mermin, Solid State Physics (Holt, Rinehart and Winston, New York, 1976).

${ }^{55}$ C. Kittel, Introduction to Solid State Physics (Wiley, New York, 1976).

${ }^{56}$ M. B. Papaconstantanopoulos, Handbook of the Band Structure of Elemental Solids (Plenum, New York, 1986), p. 73.

${ }^{57}$ F. Liu, S. N. Khanna, and P. Jena, Phys. Rev. B 43, 8179 (1991).

${ }^{58}$ G. L. Gutsev and C. W. Bauschlicher, Jr., J. Phys. Chem. A 107, 7013 (2003).

${ }^{59}$ D. G. Leopold and W. C. Lineberger, J. Chem. Phys. 85, 51 (1986).

${ }^{60}$ P. C. Engelking and W. C. Lineberger, Phys. Rev. A 19, 149 (1979). 